\title{
PROPOSTA DE ESTRUTURAÇÃO DO PROCESSO DE DESENVOLVIMENTO DE PRODUTOS PARA EMPRESAS PRESTADORAS DE SERVIÇO DE TELECOMUNICAÇÕES
}

\author{
Rodolfo Rodrigues Barrionuevo Silva, UFPR, rodolforbs@gmail.com \\ Adriana de Paula Lacerda Santos, UFPR, adrianapls1@gmail.com
}

Introdução: o setor de telecomunicações apresenta um cenário altamente competitivo e de constante inovação tecnológica, exigindo que seu Processo de Desenvolvimento de Produtos (PDP) tenha adequada estruturação e agilidade. Logo, estudou-se o PDP do setor, buscando responder: como pode ser estruturado o PDP em empresas prestadoras de serviço de telecomunicações visando obter maior eficácia e agilidade no processo? Objetivo: a pesquisa buscou propor uma estruturação do PDP para empresas prestadoras de serviços de telecomunicações. Tendo como objetivos específicos: a) mapear as etapas presentes nos principais modelos de referência de PDP a fim de fundamentar a proposta de estruturação; b) fazer um levantamento das características do setor de telecomunicações visando identificar as especificidades do setor em relação ao PDP; c) identificar quais etapas dos modelos de referência são adequadas para o PDP em empresas prestadoras de serviços de telecomunicações a partir de estudos de caso; e d) elaborar diretrizes para a estruturação do PDP dessas empresas. Método: Esta proposta foi baseada em levantamento bibliográfico e estudos de caso. No levantamento bibliográfico foram analisados: as etapas dos principais modelos de referência de PDP; os princípios e práticas ágeis de desenvolvimento; e as especificidades do setor de telecomunicações. Os instrumentos de pesquisa utilizados para coletar os dados foram: entrevistas semiestruturadas, observação direta e análise documental em duas empresas, a fim de mapear e analisar o PDP das mesmas. Resultados: Percebeu-se que havia similaridade das etapas do PDP com os modelos de referência, principalmente com o modelo de Rozenfeld et al. (2006). E que as principais diferenças estavam relacionadas: à análise de viabilidade; à avaliação pelo cliente dos conceitos preliminares do produto; e à ênfase no desenvolvimento comercial e operacional. Notou-se também que o PDP das empresas não apresentaram forte influência de práticas e princípios ágeis e que os processos de negócio mais envolvidos com o PDP foram os processos da área de estratégia, infraestrutura e produto, do framework e TOM. Finalmente, foi elaborada a proposta de estruturação do PDP para empresas prestadoras de serviços de telecomunicações, detalhando suas macrofases, fases, principais atividades, entradas, saídas e áreas envolvidas. Contribuições: Esta proposta apresentou maior abrangência quando comparada ao PDP dos estudos de caso, e, ao mesmo tempo, agregou conceitos de agilidade na sua estrutura. As características ágeis corresponderam, principalmente, a dois aspectos: a valorização da avaliação do desenvolvimento pelo cliente e a priorização do desenvolvimento simultâneo das entregas do produto. Outro aspecto destacado foi a ênfase no desenvolvimento dos quesitos comerciais e operacionais do produto, justificada pelas características dos produtos de telecomunicações. Concluiu-se que as empresas de telecomunicações estudadas precisariam investir esforços em estratégias de gestão do conhecimento para que atividades como documentação e avaliação das fases do PDP e melhoria contínua do processo, pudessem ser melhor estruturadas. Viabilizando assim, a implantação da proposta de estruturação apresentada neste trabalho.

Palavras-chave: Processo de Desenvolvimento de Produtos (PDP). Processo de Desenvolvimento de Serviços (PDS). Desenvolvimento Ágil. Setor de Telecomunicações. 